\title{
REPORMAS E PROJECTOS MONETARIOS NO BRAZIL
}

\author{
Artigo extrahido do novo «Manual \\ da Sciencia das Finanças», do dr. João \\ Pedro da Veiga Filho, Lente Cathedratico \\ da Faculdade.
}

O exame deste assumpto póde ser feito sob triplice aspecto historico. Vamos, pois, expol-o de modo mais claro e succinto, possivel, tendo em vista - o periodo decorrido desde a independencia até a promulgação da lei de 1833 , - o periodo comprehendido entre esta data até a reforma de i 846 - e, finalmente, o periodo que, deste anno, vae até o momento presente.

a) -- Primeiro periodo (I 822 a I 833). Proclamada a independencia o nosso paiz encontrava-se sob um regimen inonetario da mais completa confusão, em tudo correspondente ao regimen tributario, $(\S 76)$. Vigorava ainda a lei portugueza de 4 de agosto de I688, um dos mais antigos dispositivos a respeito e que alguns consideram assento da questão, a lei de 8 de março de I 694 que, creando, provisoriamente, uma casa de moeda na Bahia, modificou, em alguns pontos, a precedente e a lei de 4 de abril de I722, que manteve o valor da oitava de ouro de 22 quilates na base de $1 \$ 600$, para as moedas em circulação, restabelecendo assim o cambio par, ao typo de $67 \frac{1}{2} \mathrm{~d}$. sobre Londres. (I)

(I) Em I8ro, o governo tendo feito cunbar o peso hespanhol prata no valor nominal de 960 réis, valor notavelmente superior ao que devera ter tal moeda em relação ao padrão estabelecido, dahi succedeu que a moeda de prata, em razão de ser relativamente mais fraca, expelliu do mercado toda moeda de ouro e o par do cambio sobre Londres desceu praticamente a 54 pence por $\mathrm{I} \$ 000$.

Muitos entendem que semelhante cambio importou numa alteração do padrão monetario o que aliás não se deu. 
As moedas de prata cuja cunhagem chegou ter nove relaşôes com as de ouro, de par com as moedas de cobre, cujo fabrico desordenado pelo governo e particulares inundava o paiz, circulavam parallelamente e todas com o curso legal illimitado.

Offerecia-se ainda a singular anomalia de se reportarem as moedas de ouro de um só quilate e as de prata a tres padrões differentes, sendo que dois para o ouro (peça portugueza e moeda provincial) e um para a prata.

A' esta embaraçosa situação, que dava origem á enormes fraudes nas estações fiscaes, sobrelevava um agente bastardo, o papel moeda que disputava a primasia no campo da circulação. (I)

E esse papel moeda, por sua vez, compunha-se das emissões bancarias inconversiveis, de cedulas do Thesouro ou letras com prazo determinado e de conhecimento emittidas provisoriamente na falta das referidas cedulas! (2)

«Havendo desapparecido do mercado as moedas de ouro e de prata, o cambio de junho de i82.1 a julho de 1830 , desceu de 5 I a $27 \frac{1}{2}$ dinheiros por mil réis e o agio sobre metaes preciosos variava em quasi todas as provincias».

Em taes circumstancias, justificava-se uma providencia, no sentido de impedir-se as constantes fluctuações do cambio, de harmonisar-se o valor do papel moeda com o valor da moeda metallica, collocando-o em correspondencia com esta ou, numa palavra, impunha-se a regularisação do systema monetario. á Iro.

(I) C. Baptista de Oliveira, «Systema Financial do Brazil», pags. 43

(2) Dr. Leopoldo de Bulhões, «Relat. da Fazenda Federal», de 1905, pag. 31.-Amaro Cavalcanti», Reforma Monetaria», pag. 70. 
A proposito tres opiniбes notaveis se tornaram conhecidas e que são dignas de serem aqui registradas:- -a do ministro da fazenda de então, que preferia o antigo padrão portuguez e a de dois illustres parlamentares que, tendo em vista as transacções commerciaes da epoca ou a situação do mercado monetario e a necessidade de chamar para o mesmo os metaes preciosos, sustentavam o estabelecimento de um novo padrão.

Fundamentando um projecto submettido á consideração da camara dos deputados (I) para o definitivo estabelecimento do padrão de moeda de accordo com o padrão das leis portuguezas de 1688 a 1722 ( 1 oitava $=\mathrm{I} \$ 600$ ), eis como exprimiu-se o ministro da fazenda, marquez de Barbacena: «Um governo sabio e prudente deve procurar evitar grandes ou repentinas variaç̃es do cambio; porque taes variaçбes arruinam o commercio e a industria nacional, e conseguintemente diminuem ou estancam as fontes da renda publica. As pequenas variações provenientes da maior procura de letras ou metaes, ou de inesperado bloqueio ou guerra, são de facil reparação; a providencia e perspicacia dos negociantes restabelecem mui depressa o perdido equilibrio. Nenhum meio, porém, se conhece para evitar as grandes variações senão a estabilidade do meio circulante, visto que o cambio, por via de regra, nada mais é do que a medida ou proporção existente entre os valores do meio circulante de uma para outra praça. Quando as moedas metallicas são iguaes em valor, o cambio se limita ás despezas do transporte e ao juro do capital. Assim como a estabilidade dos cambios depende da estabilidade do meio circulante, assim tambem a deste de-

(I) Sessão de I de junho de 1830 . A integra do projecto ou proposta bem como os pareceres da commissão dos deputados encontram-se a pags. I 82 á 193, do «Meio Circulante», vol. 1..$^{\circ}$, do dr. Amaro Cavalcanti. 
pende do valor das moedas que devam ser cunhadas, com determinado pezo e quilate, correspondente ao valor intrinseco dos metaes. A segurança das especulações do commercio, o bom preço nos productos da industria nacional, a tranquillidade do cidadão sobre sua subsistencia, não se poderão jámais conseguir sem um bom systema monetario, sem padrão metallico a que tudo se refira. Todos sabem que o papel realisavel, á vontade do portador, é o meio circulante mais estavel, mais facil e menos dispendioso; mas, como a conditio sine qua non, para aquellas vantagens, é o troco effectivo em moeda com determinado peso e quilate, segue-se que a base da circulação e finanças de qualquer paiz consiste em um bom systema monetario, e por isso indispensavel me parece que a nossa reforma financial, ou o meio para consolidar o nosso credito, deve começar pelo vantajoso estabelecimento daquelle systema. Algumas nações, é verdade, em momentos de apuros e desgraça emittiram cobre, bronze e ferro, mas, em profunda paz e no paiz do ouro, só o Brazil apresenta o desgraçado phenomeno de pagamentos legaes em moeda de cobre».

Lançada a ideia da regularisação do systema monetario, só, em I832, foi dado parecer sobre o projecto do governo tendo a commissão parlamentar respectiva opinado, não pela manutenção do padrão de $671 / 2$ indicada, mas pela de $431 / 2$ pence, por ser essa taxa correspondente mais ou menos á depreciação, de então, do meio circulante nacional. Não se tinha em vista, segundo dizia o relator da commissão Baptista de Oliveira, alterar o valor da moeda, por isso que o antigo systema cahiu em desuso e as moedas que o representavam já não tinham o curso legal; mas tão sómente fixar, por uma maneira commoda, para os calculos e muito adoptavel ás subdivisões conhecidas 
deste padrão, uma escala rasoavel, pela qual se houvesse de regular os encargos pecuniarios da Nação dentro dos limites da renda publica.

Defendendo a ideia da fixação de um novo padrão, no que aliás divergia do ministro da fazenda, explanando principios geraes acerca do assumpto, eis como, na memoravel sessão de I 832, pronunciou-se o deputado Miguel Calmon:- «Diz-se que a fixação do ouro é uma chiméra ou absurdo, pois que o preço deste metal não depende da lei e sim do mercado. Não ha duvida que o mercado, segundo a quantidade de qualquer producto, sua utilidade e procura, é quem fixa o seu valor: este principio, em tudo verdadeiro, é applicavel, tanto ao preço dos generos como ao ouro. Entretanto, quando se trata do ouro, não como genero, mas como moeda, aquelle principio falha, deve falhar. E', pois ao ouro como moeda que a lei pode $e$ deve fixar um valor, ficando embora ao mercado darthe o que demais ou de menos deve ter como genero. (I) Chiméra e absurdo fatal haveria, si a lei, em vez de fixar o padrão monetario, segundo o qual deve o governo receber e pagar nas suas Estações, o obrigasse a estar pelo vaior que o mercado quizesse fixar cada dia. Uma compra e venda simuladas podiam constituir muito bem o preço, o valor do mercado, e dahi quantas fraudes não haveria no pagamento da renda publica e nos contractos con o Estado. O unico meio de melhorar a circulação monetaria era chamar de novo para ella os metaes preciosos que haviam emigrado; mas estes não voltariam sem que primeiro fossem resgatados o papel e o cobre, ou alterado o padrão, sendo preferivel o segundo meio; porquanto o primeiro, além de impossivel, era ruinoso, por não haver sobras de receita e nem recurso de prompto

(I) O grypho é do Autor, como alguns outros. 
para encetar proveitosamente semelhantes operações e por ser indubitavel que a passagem rapida de uma circulação forte para outra fraca ou vice-versa, produziria perdas consideraveis, não ao agricultor, não ao industrial, que regulariam seus preços pelo estado do mercaro, mas a quem tivesse contrahido obrigações em outras épocas e as tivesse de cumprir. A modificação do padrão era util; por isso que evitava a ruina a que se chegaria com o resgate, de uma assentada, do papel e cobre, e era ao mesmo tempo praticavel, bastando que, sem perda, nem inconveniente ou difficuldade, fosse ordenado e realisado por um artigo de lei.» $\mathrm{Na}$ mesma ordem de ideias pronunciou notavel discurso o membro da commissão, já referida, deputado Baptista de Oliveira que, em relação ao duplo caracter ou a dupla funcção da moeda, (I) assim exprimiu-se: "Começarei por combater novamente uma proposição por vezes avançada nesta casa, por alguns de meus collegas, um dos quaes ainda nella insiste com afinco, apezar de haver mui bem controvertida; a saber:-que os metaes preciosos, como agentes da circulação, devem ter sómente o caracter de mercadoria sem que se reportem a um padrão de valor nominal arbitrario. - O valor nominal arbitrario a um dado peso de ouro ou prata de certa

(I) Recentemente escrevemos o seguinte:-Para o fim da troca normal, da mobilisação da riqueza, ou effectividade da circulação é indispensavel a moeda, cujas funç̧ões principaes consistem em ser:-meio, medium de troca e medida de valor. Para o prehenchimento dessa dupla funcção a moeda precisa ser: a)-não só um equivalente de um valor, um valor real, intrinseco, metallico, uma mercadoria e mercadoria typo; b)-como tambem o representativo de um valor, o commum denominador de valores um méro agente de permutas, o meio de comparação, avaliação, de numeração e pagamento, um padrão commercial. - Assim como o kilogramma e o metro são medidas invariaveis do peso e da extenção-a moeda (embora não absolutamente invariavel) é um padrão de valor ou melhor uma medida do valor e por isso denominada valorimetro.-Alguns economistas como Stanley Jevons entendem que aquelles requisitos são outras tantas funcções da moeda. 
lei, tomado como padrão de valores, nenhuma outra cousa é mais do que uma escala, pela qual se.tornam comparaveis entre si, quaesquer fracções deste todo; e serve por este modo ao governo, que a tem adoptado, afim de por ella regular com a maior exactidão e, em todas as combinações possiveis, as suas transacções pecuniarias, activas e passivas. Commummente, uma vez restabelecida pelos governos semelhante escala, os particulares a adoptam no trato mercantil, mas tão sómente com o fim de irem de harmonia com os usos nacionaes, como acontece a respeito do systema de peso e medidas. Notarei, mais que a pratica de dar-se ao padrão monetario um valor nominal, que alguns economistas levianamente censuram, taxando-se até de absurda, não é vicio herdado dos tempos barbaros, $e$, pelo contrario, uma importante descoberta, que muito honra a civilisação, moderna. Nas moedas greyas e romanas, apenas se descobrem alguns vestigios de semelhante ideia: e mesmo nos começos da nova civilisação européa, a moeda era calculada em relação ao peso; sirva de exemplo a libra ingleza ou antes a franceza, nos primeiros tempos desta monarchia, e suas denominações; o que hoje passa por uma méra linguagem, indicava então o peso da prata desse mesmo nome e suas fracções. Não levarei mais longe a demonstração da conveniencia de uma pratica geralmente adoptada por todas as nações cultas. E' portanto indispensavel a fixação de um padrão monetario, no sentido que venho de explicar, afim de servir de typo ás transacções do governo, e mesmo para uso do commercio.»

Os principaes adversarios dessa reforma de 1833 , foram os marquezes de Baependy e de Barbacena e o conselheiro Araujo Lima, mais tarde marquez de 
Olinda, que opinavam pela manutenção do padrão estabelecido pela antiga lei portugueza. (I)

O marquez de Baependy, depois de referir-se ao cambio par e ao cambio corrente, disse:- «E' verdade que, passando a dar-se a uma oitava de ouro de 22 quilates o valor de $2 \$ 500$, emquanto não houver nova lei em contrario, se ha de logo estabelecer um cambio par entre as moedas das diversas nações muito differente do actual, que é de $671 / 2$ por $1 \$ 000$; mas o cambio corrente sem duvida ficará fóra do alcance da lei, e deverá referir-se ao novo cambio par, ou para mais ou para menos, como se referia ao antigo, cessando por consequencia a pretendida vantagem de termos o cambio fixo.»

A opinião do marquez de Barbacena foi a seguinte: «Nenhum poder humano é capaz de fixar o valor dos metaes preciosos, quando ha em circulação papel-moeda e cobre debaseado. Pretender em taes circumstancias fixar o valor do ouro por uma lei, seria o mesmo que pretender por lei regular os das de chuva, seus gráos de calor e de frio em cada dia. «O absurdo da pretenção é identico, mas o resultado das duas leis seria muito differente. A que se publicasse, regulando a chuva e o frio, não perturbaria o curso das estações: ellas seguiriam as leis naturaes sem a menor contemplação com as disposições da Assembléa Geral e toda a perda seria a do tempo da discussão e despeza da impressão. A lei, fixando presentemente o valor do ouro a $2 \$ 500$ a oitava, tambem não fixaria nern cambio, nem valor de metaes; tudo seguiria o curso determinado pela opinião publica da praça. Para as transacções futuras a lei será completamente

(1) Dr. Leopoldo de Bulhões, "Relat. da Fazenda Federal» de I905, pags. 38 e seguintes, onde vem melhor desenvolvido o assumpto.-Dr. Amaro Cavalcanti, «Meio Circulante Nacional», vol. I. , pags. 290 á 3 I4. 
nulla; nos contractos, porém, anteriormente feitos causará damno irrreparavel a todos os credores.

Assignalando a inopportunidade da reforma e $a$ pretenção de querer-se quebrar o padrão monetario, mantendo-se ao mesmo tempo o papel inconvertivel, disse o conselheiro Araujo Lima: -- «Na Inglaterra, esse exemplo que se nos apresenta a cada passo, fez-se o contrario do que nós queremos. Ali, de facto, elevou-se a moeda; a lei produziu a alteração de valores, a Fazenda Publicá ficou gravada e os particulares prejudicados; mas ali mandou-se realmente contar por moeda forte, e nós nada propomos que se assemelhe com isto; ao contrario, queremos que continue, ainda por tempos, a moeda fraca, e que só o commercio e o curso natural das cousas restabeleçam o preço natural, e que isto não seja por effeito de lei, o que será sempre desastroso. E', por tanto, tendo mesmo em vista o que aconteceu na Inglaterra e para evitar os males que ali se sentiram, que nós não queremos que se toque nesta materia, mas sim que tudo seja obra do tempo por meio de medidas indirectas, que nos deem bom resultado.»

Após uma longa e memoravel discussão travada no seio do parlamento nacional, nos annos de $1832 \mathrm{e}$ I833, no qual realisou-se uma assembléa geral legislativa, convocada extraordinariamente para a discussão e solução da questão do meio circulante, fez-se a reforma no sentido da modificação do padrão monetario para o typo de $43 \frac{1}{1} 2$ (a oitava do ouro de 22 quilates $=2 \$ 500$ ) tendo aliás se manifestado préviamente de accordo o então ministro da fazenda (I) cons.

(I) $\mathrm{O}$ marquez de Barbacena foi ministro da fazenda do gabinete de 4 de dezembro de 1829 e serviu até 2 de outubro de 1830 e o conselheiro Candido José de Araujo Vianna (marquez de Sapucaby) foi ministro do gabinete de 13 de setembro de 1832 e serviu até 2 de junho de 1834 . «Programmas Ministeriaes de 1822 a 1889 », pags. 25 á 45 .

-O relatorio do ministro Araujo Vianna, propondo a reforma do padrão, tem a data de $\mathbf{2}$ de abril de 1833 . 
Araujo Vianna que, com Francisco de Lima e Silva e João Braulio Muniz referendaram a-Lei n. 59, de 8 de outubro de 1833. (I)

b) - Segundo periodo (I 833 a I 846). Realisada a reforma seguiu-se á mesma um periodo que veio impedir os beneficos resultados esperados. (2) A situação politica era toda de agitações e luctas fratricidas, a administração publica em pleno regimen do deficit e o papel-moeda se avolumando, dia a dia, a ponto de duplicar o seu quantum, chegando em i 846 a cerca de 60 mil contos, incluindo-se no calculo 9 mil contos de letras do thesouro. $\mathrm{O}$ cambio continuava com as bruscas oscillações, baixando successivamente, e indicava-se como principal remedio a tão difficil situação o resgate do papel-moeda, o qual já tinha sido objectos das leis de 8 de outubro de 1833 , art. 5 , e da lei 6 de outubro de I835, art. I3. Foi promulgada a lei n. Io9, de I I de outubro de I 837 que, como as anteriores, estabeleceu uma renda destinasda a $\odot$ resgate, até que o valor do papel se equiparasse ao do padrão monetario. Todos os esforços, porém, nesse sentido, foram inuteis e o melhoramento do meio circulante não se tinha obtido.

O ministro da fazenda de então, conselheiro Alves Branco vendo o insuccesso da reforma e o cambio

(I) «Collecção das Leis do Rrazil» de I 833, vol. I., pag. I02. A' esta lei precedeu a de 3 do mesmo mez e anno, a qual mandou substituir toda moeda existente, de cobre e cedulas recebiveis nas repartições publicas. Da mesma fórma que a lei de 27 de novembro de 1827 , segundo a qual pela, vez primeira, emittiu-se o papel-moeda do thesouro nacional.

(2) $\mathrm{O}$ art. $\mathrm{I}^{\circ}$ dessa lei e onde se contem a disposição geral e póde-se dizer unica do systema, reza assim:- «Na receita e despeza das estações publicas entrarão o ouro e a prata em barras ou em moedas nacionaes ou extrangeiras a $2 \$ 500$ por oitava de ouro de 22 quilates». Com a presente disposição teve o legislador sem duvida em vista dar aos metaes amoedados um valor, correspondente, quanto possivel, ao preço corrente do mercado para os mesmo, mas tão incompleto é o texto da lei, encarada como reforma monetaria geral que referindo-se no seu citado artigo a ambos os metaes nem siquer declarou o valor da prata em correspondencia com o fixado para o outro metal. Dr. Amaro Cavalcanti; «Reforma Monetaria», pag. 7 I. 
cahir até quasi $25 \mathrm{~d}$, e temendo que continuasse a descer até a taxa de 5 d., (I) em seu relatorio opinou por uma nova alteração do padrão, propondo que o ouro de 22 quilates valesse $4 \$ 000$ a oitava.

Estando de accordo com a ideia suggerida pelo ministro Alves Branco, o senador Bernardo Pereira de Vasconcellos, na sessão de I 7 de junho de I 846 , apresentou um projecto, que mantendo o padrão de i 833 e visando attrahir para o mercado as especies metallicas, foi concebido nestes termos:-- I. ${ }^{\circ}$ os pagamentos nas Estações Publicas e entre os particulares deviam, a principiar em janeiro de i 847 , ser effectuados em papel-moeda, na razão de $4 \$$ \$ooo por oitava de ouro, ou na moeda de ouro e prata que o governo designasse, mas pelo mencionado valor; $2 .^{\circ}$, ficava o governo autorisado a retirar da circulação a somma de papel necessario para eleval-o ao sobredito valor, fazendo para esse fim as operações de credito indispensaveis; $3 .{ }^{\circ}$, retiraria o governo, annualmente, da circulação a quantia de mil contos de papel-moeda pelo mencionado valor; $4 .^{\circ}$, seriam observadas as obrigações sobre pagamentos contrahidos anteriormente á nova lei ; $5^{\circ}$, continuaria, em pleno vigor, o padrão monetario fixado na lei de 8 de outubro de 1833 .

A commissão do senado enćarregada de dar parecer sobre o projecto aceitou-o, menos na parte referente ao padrão monetario que lhe parecia dever ser modificado. A discussão mais importante que houve a respeito do projecto foi na Camara, onde se manifestaram, a favor do mesmo, Hollanda Cavalcanti, Vasconcellos, Souza Franco e Souza Martins e, contra, Souza França, Souza Oliveira, Rebouças e outros.

- Hollanda Cavalcanti que, no ministerio da fazenda, vinha de succeder a Alves Branco e cujo pro-

(1) Este terrivel prenuncio veio afinal dar-se em 23 de abril de r898! 
gramma de governo era gastar o menos possivel e arrecadar o mais que pudesse-, considerou o projecto como um remedio para a estabilidade do meio circulante.

Vasconcellos dizia:- «O projecto tem em vista, como se féz ver, livrar o papel-moeda, unico meio circulante do paiz, da constante fluctuação em que anda, não consentindo que baixe nem que suba acima do seu actual valor.» «O projecto chama indirectamente o ouro e a prata ao mercado, porque o desembaraça da superabundancia do papel; esses metaes vão lentamente occupando o seu posto offerecendo-se ao papel como amigo, como um alliado para o coadjuvar nas permutações.» (I)

Souza Martins que, na sessão de 2 de setembro de 1846 , defendeu vigorosamente o projecto assim exprimiu-se:- «Quando um paiz tem diversas circulações das quaes uma é muito mais enfraquecida que outra, ou por outras palavras, quando um paiz tem uma circulação de papel-moeda que representa valores muito inferiores á moeda metallica ha dois methodos de restabelecer a circulação monetaria:-um é fazer elevar o papel circulante ao valor primitivo da moeda metallica que elle representa, outro é resgatar o papel pelo valor médio que elle tem na circulação:-o projecto adoptou este ultimo methodo. O nobre deputado pelo Rio de Janeiro entende que o papel em circulação deveria ser resgatado paulatinamente á pro-

(1) Refere o dr. Amaro Cavalcanti que pelo discurso deste deputado se verifica que o que se pretendia em vista das boas condições do mercado e do cambio que então faziam affluir o ouro para o nosso paiz ao preço corrente de cerca de $4 \$ 000$ por uma oitava (e pouco menos)-era se mandasse receber nas estações publicas aquelle metal pelo referido valor, afiın de por esse meio attrabil-o e conserval-o em razão maior nas transacções, e obtido este resultado tomal-o para ensejo de converter todo papel-moeda circulante em especie metallica. O seu intento fôra, pois a conversão metallica e não o estabelecimento de um novo padrão. «Meio Circulante Nacional», vol. 2., pag. 60. 
porção que fosse augmentando de valor até elevar-se ao cambio de $431 / 2$ conforme o padrão actual estabelecido pela lei. Eis aqui a divergencia entre os dois processos: um quer elevar o meio circulante paulatinamente até chegar ao padrão monetario estabelecido pela lei; o outro quer conservar o meio circulante conforme o valor que elle tem actualmente no mercado e prevenir as maiores ou menores oscillações que possa ter esse valor, fixando de uma maneira a mais approximadamente possivel a um valor constante, porque fixar o valor da moeda corrente de um modo invariavel e sempre o mesmo é impossivel. Ainda mesmo quando o meio circulante é só metallico o cambio oscilla sempre continuamente entre umas e outras praças commerciaes segundo são devedoras ou credoras; por consequencia fixal-o de uma maneira invariavel nenhum legislador o póde conseguir, o que só devemos pretender é fixal-o de maneira menos variavel possivel e é este o fim a que tende o projecto em discussão.» (I)

Entre os que combateram o projecto salientaram-se:-Souza França «entendia não poder o governo fixar o valor da moeda pelo facto de o ouro seguir a sorte de todos os generos que andam no mercado.» (2) - Rebouças que, criticando o projecto sobre o ponto de vista constitucional por deixar ao governo a faculdade de estabelecer a relação entre o ouro e a prata e pelo vago de sua reducção que permittia e não obrigava o governo a receber o ouro por certo preço sem cogitar da hypothese do papel valer mais do que o ouro, entendia que o unico processo de melhorar o meio circulante era a fundação de um

(I) Sessão da Camara, de 2 de setembro de 1846.

(2) Sessão da Camara, de 31 de agosto de 1846 . Esta objecção já rebatida por Calmon por occasião da discussão da reforma de 1833 foi pois reproduzida. (Vide pagina 139 deste livro). 
banco emissor de notas conversiveis em metal á vontade do portador (I) e Souza Oliveira que, entre outros pontos, analysou o projecto sobre o seguinte ponto de vista:- «O nobre deputado concorda, portanto, que para resgatar o papel todo em circulação, tomando-se por base o valor que elle tem actualmente, nâo é necessario alterar o padrão monetario do paiz. Eu tenho ouvido alguns senadores que tem approvado esta ideia de alteração do padrão monetario, argumentar com a operação que se fez na Austria. E' um engano manifesto; a operação que se fez na Austria conservou o padrão monetario adoptado; ordenou-se o resgate de todo o papel pelo preço da actualidade, que era $25^{\circ}$ por cento, autorizou-se o banco a fazer esse resgate dando no seu papel realisavel á vista, por moeda forte I florin por $2 \frac{1}{2}$ florins de papel-moeda; os pagamentos continuaram da mesma maneira a serem feitos em moeda forte. Portanto, não será necessario que se altere o padrão monetario do paiz, para satisfazer-se a necessidade de resgatar-se todo papel.. Eu entendo que uma vez estabelecido o padrão monetario por uma lei, toda alteração é uma falta de fé, não é objecto que se deva mudar nunca e todos os governos que o têm feito, têm sido victimas dessa medida, por terem faltado á fé publica. Nós podemos tomar o facto existente quanto ao resgate papel, mas não quanto a alterar o padrão da moeda.»

O projecto foi afinal convertido na lei n. ${ }^{\circ} 4 \mathrm{Or}$, de I I de setembro de 1846 , cuja integra é a seguinte: -Art. I. -De r. ${ }^{\circ}$ de julho de 1847 em diante ou antes se fôr possivel, serão recebidos nas estações publicas as moedas de ouro de 22 quilates, na razão de $4 \$ 000$ por oitava e as de prata na razão que o governo determinar. Esta disposição terá logar nos pa-

(I) Sessão da Camara, de 2. de setembro de 1846. 
gamentos entre os particulares. Art. $20^{\circ}-\mathrm{O}$ governo é autorisado a retirar da circulação a somma de papelmoeda que fôr necessario para eleval-o ao valor do art. antecedente e nelle conserval-o; para esse fim poderá fazer as operações de credito que forem indispensaveis. Art. 3. - Serão observadas as convenções sobre pagamentos. Art. $44^{\circ}-$ Ficam revogadas as disposições em contrario. (I) Esta lei foi considerada pelo ministro da fazenda, Rodrigues Torres, em seu relatorio de I 850 , como um dos actos mais judiciosos da legislação brazileira, todavia como obra humana não deixa de ter defeitos e entre os principaes está o de não estabelecer, de modo positivo, o regimen do bimetallismo como a lei de 1833 e nem regular, desde logo, o bimetallismo a cujo regimen tanto se approximou. (2)

Ao contrario do que succedeu em i 833, a reforma monetaria de $\mathrm{r} 846$ foi de successo, (3) por ter-se seguido um periodo de devolvimentos das forças

(r) As principaes leis monetarias complementares e posteriores á reforma foram as seguintes:-a de 20 de setembro de $184 \%$, que mandou cunhar moedas de ouro e de prata de differentes valores; o dec. de 28 de julho de I849, que fixou o toque, peso e valor das moedas;-o dec. n. 2004, de 24 de outubro de 1857 , que reconheceu a libra esterlina como moeda nacional; a lei de 3 de setembro de 1870 , mandando fabricar moedas de nickel e outras.-A lei n. 40I, encontra-se na collecção das leis do Brazil, anno 1846, vol. $\mathrm{r}^{\circ}$, pag. 70 .

(2) O dr. Vieira Souto, em sua «Conferencia sobre a situação economica do paiz em 19 de setembro de I9OI», manifestou-se contra as reformas de 1833 e 1846 , dizendo o seguinte:- - Estas duas quebras de padrão monetario brazileiro representam o primeiro erro que commetteram no intuito de evitar a fuga do metal existente no mercado, attrahir o ouro dos paizes extrangeiros, valorisar o papel-moeda e elevar a taxa cambial. Não carece demorar-se o orador na demonstração de semelhante erro; todos comprehendem que a mudança da denominação dada a oitava de ouro no nosso regimen monetario, não podia alterar-lhe o valor real.» Outros entendem que não houve erro, visto não tratar a reforma de alterar o valor real, mas sim o valor convencional adoptado nos respectivos padrões de 1833 e 1846 .

Vide os discursos de Baptista de Oliveira e Miguel Calmon á pag. I39

(3) Na occasião da reforma o cambio estava a $27 \frac{3}{4}$ e dahi por diante foi melhorando sensivelmente com fracas oscillações até 1857 , dahi em diante começou o exodo do ouro e a insufficiencia do padrão nacional. 
productoras do paiz, de uma real prosperidade economica. (I)

Do exposto se conclue, em synthese, o seguinte:

I.-A reforma monetaria de 1833 , tendo por fim adoptar um padrão entre os que existiam, impunha-se pela conveniencia de se por termo á anarchia economica no regimen da circulação;

II.-A reforma de i 846 , fôra, sem duvida uma necessidade, sobre tudo em vista do seu manifesto intento de dar ao ouro amoedado um valor correspondente á alta do seu preşo, como mercadoria, a esse tempo, no paiz; (2)

III.-Ambas se justificam pelo intuito de attrahir para a circulação os metaes preciosos para estabelecer-se o regimen da convertibilidade-o que, no correr do tempo, não se conseguiu pelo facto das successivas emissões do papel-moeda (3) e insufficiencia da producção nacional. (4)

-d) Terceiro periodo ( 1846 a I 90 ? ). No decurso deste periodo a ideia de uma nova reforma mo-

(I) Hollanda Cavalcanti, Relatorio da Fazenda apresentado em 1847 Ali se encontra um resumo dos resultados da reforma.

(2) Dr. Amaro Cavalcanti, "A Reforma Monetaria», pag. 73. A pag. 83 accrescenta este autor:- «Uma das razões basicas para qualquer reforma monetaria é tornar o valor do metal cunbado na maior correspondencia possivel com o preço corrente do mesmo como mercadoria.»

(3) Quando a lei foi promulgada o papel circulante era de $56 \mathrm{mil}$ contos inclusive 6 , de bilhetes do thesouro.

(4) O dr. Leopoldo de Bulhóes, actual ministro da fazenda, em um estudo completo sobre as reformas monetarias em nosso paiz, no «Relatorio da Fazenda Federal» de 1905, pags. 30 á 65 com muito acerto assim conclue:«Do esboço historico que se acaba de fazer se deprehende que a elevação do valor dos metaes preciosos não influiu no melhoramento do meio circulante, e, conseguintemente, na fixação do cambio. Este regula-se pelo maior ou menor saldo entre os valores remettidos e os valores recebidos, pela maior ou menor procura de letras, e pela maior ou menor confiança que inspira a situação politica e commercial do paiz.

O enfraquecimento da moeda não trouxe senão por pequeno espaço de tempo os metaes nobres ao mercado, emquanto o papel foi mais apreciado e teve agio sobre elles». 
netaria pouco preoccupou a attenção dos estadistas do segundo reinado, o que aliás se justifica tambem pelas condiçð̃es economicas e financeiras do paiz. Em i 886 o assumpto foi apenas lembrado pelo ministro da fazenda conselheiro Francisco Belizario que suggeriu a modificação do padrão para o typo de $24 \mathrm{~d}$ = = $\$$ \$ooo, visto estar elle de accordo com a situação existente ou a média das cotações em quasi todo o longo estadio de 1846 até aquella data.

Em seu «Relatorio da Fazenda Imperio» de I886, á pag. I6, escreveu o seguinte:-«Não é de hoje que o preço do ouro acha-se em disparidade com o seu valor e que o estado do cambio nos é adverso. A nota de $20 \$ 000$ não recebe em troco cinco oitavas de ouro, porém muito menos; o cambio não é cotado a 27 d. por um mil réis e $\operatorname{sim}$ a 22 d., sendo que ainda ha pouco a cotação descera a I $7 \frac{1}{2} \mathrm{~d}$. A nota não é mais medida legal de valores; não compra no mercado a quantidade ou peso de ouro, que representa. O cambio não póde firmar-se; faltam-lhe para correctivo natural, a importação e exportação de metal; acha-se sujeito unicamente á lei do offerecimento e procura de cambiaes, ás correntes de confiança ou desconfiança, e pois em constantes fluctuações. A causa de todas estas perturbações está no excesso do papel-moeda.»

Em seu relatorio de $\mathrm{I} 887$, o mesmo ninistro, fazendo identicas considerações e referindo-se a necessidades de resgatar-se o papel-moeda e de lançar-se as bazes da circulação metallica, suscitou a ideia da modificação do padrão monetario para o referido typo de 24 d. Assumpto que não foi mais discutido nem resolvido até a proclamação da Republica.

Instituido o novo regimen politico, em sessão do senado federal de 8 de agosto de r89i, o dr. Amaro 
Cavalcanti, sustentando que a reforma de i 846 não fundou no paiz um systema monetario capaz de subsistir com os requisitos de adaptação convenientes ás nossas condiç̃es peculiares sobre a especie, apresentou um projecto modificando o actual padrão, de modo à oitava de ouro amoedado ter o valor de $4 \$ 500$ o que nas relações cambiaes corresponderá a 24 d.= I \$ooo. Na exposição de motivos a que fez preceder ao projecto, o dr. Amaro Cavalcanti, entre outros itens, sustentou: a) - a opportunidade de termos uma reforma monetaria comprehensiva das differentes especies metallicas; b) - a necessidade de tirar-se do isolamento o nosso systema actual e pôl-o em correlação com o systema francez, que parece tender a tornar-se universal; c)-a conveniencia de fixar $o$ valor dos metaes amoedados em correspondencia com o seu serviço de mercadoria e a vista das nossas relações cambiaes com o extrangeiro; e conseguintemente facilitar a cunhagem da moeda nacional.

A ideia ficou apenas lançada e foi adoptada por diversos economistas praticos sem ter sido levada a effeito nem discutida amplamente. (I)

(I) A ideia de modificar-se o titulo da moeda brazileira, afim de tornal-a correspondente aos systemas da maioria dos povos cultos tem sido estudada pelos drs. Ennes de Souza e Corrếa da Costa, ex-directores da Casa da Moeda, e dr. Borja Castro, lente da Escola Polytechnica do Rio.

Em 1902 a commissão de finanças da Camara dos deputados, da qual foi relator dr. Serzedello Corrêa, emittiu breve parecer contrario á emenda ao orçamento apresentada pelo deputado dr. Alves Brito para a fixação do padrão em 24 d. por mil réis. A emenda foi rejeitada.

-O snr. Edmond Théry, redactor chefe do «E'conomiste Européen», autor das «Finances et le Change du Brésil», em I904, publicou um trabalbo sobre a «Réforme Monetaire et de Création d'une Banque d'Emission au Brésil», que mereceu honrosas referencias do conselheiro Angelo do Amaral e Lourenso de Albuquerque no "Jornal do Commercio» de 27 de janeiro e i7 de fevereiro de 1905 e uma critica do dr. Leite Oiticica, na mesma folha no correr do mez de fevereiro do referido anno. O snr. Edmond Théry concluiu seu livro sobre a reforma monetaria apresentando dois projectos para a fixação do padrão monetario em 12 d. por um mil réis (ou a uma taxa inferior) e a instituição de um banco emissor com previlegios especiaes, para o fim do estabelecimento da circulação metallica. Esse trabalho cuja apreciação não 
No momento presente continúa a ser agitada a questão da modificação do padrão monetario vigente, para menos ainda do typo de 24 d., suggerido pelo conselheiro F. Belizario, julgando alguns que, sem essa providencia, não se poderá conseguir a fixação do valor do meio circulante em nosso paiz. Convencidos que, para obter-se uma certa estabilidade no cambio ou uma conversão real e facultativa como na Russia, a um typo dado, não é necessaria a quebra do padrão monetario, (I) o que nos dispensamos de demonstrar por ser intuitivo e mais do que elementar, nos reportamos ao § I I 2 onde o assumpto da valorisação e resgate do meio circulante é examinado.

$$
\text { João Pedro da Veiga Filho. }
$$

permitte os estreitos limites deste livro, constitue uma contribuição para o exame e estudo da questão monetaria que constantemente vemos agitada em um paiz.

- O corretor Arthur Hitcheing, publicou, um folheto e differentes artigos no «Jornal do Brazil» de 10, I5, 22 e 29 de novembro de 1896 e «Jornal do Commercio» de 22 de fevereiro de 1903, sobre o assumpto, apresentando um projecto de refórma monetaria tomando por base o cambio de $\mathrm{I}_{5} \mathrm{~d}$. por mil réis.

- Tambem o dr. Alexandre Góes, em r 899, escrevendo um livro sobre o «Resgate do Papel Moeda», consagrou uma parte á refórma monetaria, pags. I03 e segs., tomando por base o typo de 18 d. por mil réis.-Esses estudos referidos são dignos de consulta.

(I) Já em I846 sabia-se que valorisação do meio circulante não implicaria a quebra do estalão monetario do paiz. O senador Bernardo Pereira de Vasconcellos, ao apresentar, em 17 de junho de 1846 , o projecto da reforma monetaria estabelecendo que o papel circulante não fosse mais cotado a $2 \$ 500$ por oitava de ouro, mas a $4 \$ 000$, e dispondo para o resgate nesta base, cli ramente exigiu no art. $5 .^{\circ}$ do projecto- -que o padrão monetario, fixado na lci de 8 de outubro de 1833 , continuaria em seu pleno vigor». 